\title{
How Election Polls Shape Voting Behaviour
}

Dahlgaard, Jens Olav ; Hansen, Jonas Hedegaard; Hansen, Kasper Møller; Larsen, Martin Vinæs

Document Version

Accepted author manuscript

Published in:

Scandinavian Political Studies

DOI:

10.1111/1467-9477.12094

Publication date:

2017

License

Unspecified

Citation for published version (APA):

Dahlgaard, J. O., Hansen, J. H., Hansen, K. M., \& Larsen, M. V. (2017). How Election Polls Shape Voting

Behaviour. Scandinavian Political Studies, 40(3), 330-343. https://doi.org/10.1111/1467-9477.12094

Link to publication in CBS Research Portal

\section{General rights}

Copyright and moral rights for the publications made accessible in the public portal are retained by the authors and/or other copyright owners and it is a condition of accessing publications that users recognise and abide by the legal requirements associated with these rights.

Take down policy

If you believe that this document breaches copyright please contact us (research.lib@cbs.dk) providing details, and we will remove access to the work immediately and investigate your claim. 


\section{How Election Polls Shape Voting Behaviour \\ Jens Olav Dahlgaard, Jonas Hedegaard Hansen, Kasper Meller Hansen, and Martin Vinæs Larsen}

Journal article (Accepted manuscript*)

\section{Please cite this article as:}

Dahlgaard, J. O., Hansen, J. H., Hansen, K. M., \& Larsen, M. V. (2017). How Election Polls Shape Voting Behaviour. Scandinavian Political Studies, 40(3), 330-343. D0I: 10.1111/1467-9477.12094

This is the peer reviewed version of the article, which has been published in final form at Dol: https://doi.org/10.1111/1467-9477.12094

This article may be used for non-commercial purposes in accordance with Wiley Terms and Conditions for Self-Archiving

* This version of the article has been accepted for publication and undergone full peer review but has not been through the copyediting, typesetting, pagination and proofreading process, which may lead to differences between this version and the publisher's final version AKA Version of Record.

Uploaded to CBS Research Portal: February २०19 


\title{
How Election Polls Shape Voting Behavior ${ }^{1}$
}

\author{
SCANDINAVIAN POLITICAL STUDIES (EARLY VIEW) \\ Preprint manuscript \\ Ph.d.-stud. Jens Olav Dahlgaard, Ph.d.-stud. Jonas Hedegaard Hansen, Professor Kasper M. \\ Hansen \& Ph.d.-stud. Martin V. Larsen \\ *University of Copenhagen, Department of Political Science, \\ Øster Farimagsgade 5, DK-1353 Copenhagen K, Denmark \\ E-mail: jod@ifs.ku.dk,jhh@ifs.ku.dk,kmh@ifs.ku.dk\&mvl@ifs.ku.dk.
}

\begin{abstract}
We investigate how election information such as opinion polls can influence voting intention. The bandwagon effect claims that voters 'float along': a party experiencing increased support receives more support and vice versa. Through a large national survey experiment we find evidence of a bandwagon effect among Danish voters. When voters are exposed to a news story describing either an upwards or downwards movement for either a small or large party, they tend to move their voting intentions in the according direction. The effect is strongest in the positive direction, i.e., when a party experiences increased support more follows. We find consistent effects across two different parties, for a diverse national sample in a political context very different from those that have characterized earlier research on the bandwagon effects. Considering previous research and the fact that we do not find evidence that suggests that the effect of polls vary across sociodemographic groups, our results imply that bandwagon behavior is based not on social or political contingencies, such as media or political institution, but on fundamentals of political cognition.
\end{abstract}

Keywords: Experiments; Election polls; Perception of polls; Bandwagon effect; Voting behavior; Media effects 
Election polls are a ubiquitous part of modern political life both in terms of the sheer number of polls, and the extent to which these polls find use in political reporting in the news media. This is potentially important for understanding how voters decide which candidates and parties' to vote for in elections. As such, we know that people tend to favor and conform to strong groups (e.g. Leibenstein 1950), and in politics, one of the best metrics for which political groups are gaining in strength are election polls. Accordingly, election polls might not just be tracking movements in the electorate. To some extend they might lead the electorate towards the candidates, who are already gaining electoral momentum, by conveying to the electorate a sophisticated map of this momentum. What is conventionally called a bandwagon effect (Gallup \& Rae 1940; Simon 1954; Bernays 1945; Field et al. 1945; Marsh 1985).How polls and their public dissemination might influence the voters and, in turn, the election result has fueled academic debate about the excessive use of polls (cf. Donsbach 2001; Aalberg \& van Aelst 2014; Petersen 2012). There has also been a long vigorous public debate on these issues (e.g., Jakobsen et al. 2005; Ditlevsen 2009).

Recently, this debate has been fueled in the Nordic countries by an exit poll published by the leading Danish Broadcast Service (DR) before the polling stations had been closed on election day in November 2013, which eventually ended up substantially underestimating the Social Democrats. Following this, politicians have suggested that the media should stay away from publishing opinion or exit polls shortly before an election (Albrechtsen 2013; Skjoldan 2015). In Sweden, the Center Party have on multiple occasions proposed that the Parliament (Riksdagen) should decide to prohibit the publication of opinion polls in the days ahead of elections (Hernadi 2010). Similarly, polls seem to steer political discourse. For instance, in the 2013 election in Norway the Socialist Left Party's bad polling results up to the election caused the party leader to encourage voters to rally around the party (Sandvik et al. 2013). 
In spite of these concerns the existing empirical literature investigating whether and how election polls affect voting behavior is limited in several ways. As such, much empirical research is dated, often conducted with quite small convenience samples, and almost all of it is conducted in contexts with a few large parties and in countries using the first-past-the-post system (e.g. US, UK and Canada) (Hardmeier 2008). Recently new studies have revitalized the importance on how polls influence vote choice with causal designs and in new contexts. These studies all confirm bandwagon effects in different countries such as the Netherlands, France, Austria and Germany (Van der Meer et al. 2016; Meffert et al. 2011; Stolwijk et al. 2016; Morton et al. 2015). With a strong causal design in a new context, we situate our research note with these recent contributions to further expand the scope of the bandwagon effect and replicate it in yet another context with its distinct political culture.

We conduct a large-scale survey experiment on a national representative sample in Denmark, a multiparty context with proportional representation, to see if Danish voters also join the bandwagon. Specifically, we test if the content of a poll and its reporting affects voting intentions. Our design has three distinct advantages over earlier studies. First, the large number of respondents and low number of treatments allows us to detect smaller effects. A feature which is necessary since previous literature have struggled to find consistent results, arguably, because of the large sampling variability of effect sizes which come with small samples (Hardmeier 2008). Second, the Danish context of a consensus-oriented, multi-party system with proportional representation allows us to look for the bandwagon mechanism in a political system quite different from most of the existing research. In a two-party context, if one party seems to be moving ahead, joining the party could mean joining the winner. In a multiparty context, a party might independently experience an electoral boost, while its coalition partners experience a setback. ${ }^{2}$ Third, and related to the merits of our multiparty context, we test whether the effect of opinion polls is consistent across different 
types of parties, using both a large executive party and a small opposition party, and across different types of citizens, analyzing whether factors such as gender and age moderate the bandwagon effect (Dahlgaard et al. 2015; Dahlgaard et al. 2016).

\section{Polls and voting behavior: The bandwagon effect}

Since the first scientific polls, there has been an ongoing debate on whether and how polls influence voters (Gallup \& Rae 1940; Simon 1954). One of the most common hypotheses has been that polls have a so-called bandwagon effect. The bandwagon effect implies that when a person identifies with a social group and observes that it is moving in a certain direction, she will want to move in the same direction (Simon 1954; Marsh 1985). In terms of polls, this means that voters will be inclined to follow the tendencies outlined in these polls, if there is any clear pattern of movement, and polls can in this way become self-fulfilling prophecies (Rothschild \& Malhotra 2014). Specifically, voters will be more likely to support a party if it is clearly on the rise in the polls, and they will be less likely to support a party if it is clearly declining in the polls. Since our short research note does not allow for a comprehensive review of the literature we refer readers to the recent review in Van der Meer et al. (2016) or Hardmeier (2008).

There are several plausible social psychological mechanisms which could imply a bandwagon effect. Firstly, belonging to a strong group may be associated with a sense of happiness, confidence and satisfaction for the voter, and accordingly voters might try to be part of such groups (Mondak 2010; Brady \& McNulty 2011; Gerber et al. 2011; Erikson \& Stoker 2011). Secondly, voters could believe it wise to follow "the wisdom of the crowds", believing that the electorate as a whole is more able than the individual voter to understand the complexities of choosing the best and most competent candidate or party (Lau \& Redlawsk 2001; Hardmeier 2008). Thirdly, people might 
change their attitudes in response to information from election polls so that when the election result is actualized, they can easier resolve cognitive dissonance induced by experiencing an election result where their most preferred party has lost, a phenomena also known as "sweet lemons" (Kay et al. 2002: 1302; Mutz 1997).

Empirically, a number of studies have tried to link trends in polls to political behavior (see Hardmeier, 2008 for a meta-study and a review). However, while these studies in general point towards a bandwagon effect, and as such have broken ground on this important topic, they have several limitations. For instance, few studies have looked at national and diverse samples (cf. Rotschild \& Malhotra 2014); instead, they have relied on convenience samples (e.g. Ceci \& Kain 1982). Further, the few studies which have used national samples often do not rely on an experimental design, making causal inference unlikely (Hardmeier 2008; Kleinnijenhuis et al. 2007). Finally, a number of these studies investigate opinions rather than voting intentions leaving the key issue of this research note unresolved (e.g. Ansolabehere \& Iyengar 1994). Namely, whether polls actually affect voting intentions for political parties. Our study tries to exceed these limitations by providing an experimental test of the bandwagon hypothesis with a large and diverse national sample using intended voting behavior as the primary dependent variable while also providing evidence for how sympathy and support for the parties are moved.

The context of the existing studies provides additional reason for the timeliness and relevance of the experiment presented here. Most importantly, almost all previous studies of the bandwagon effect have centered on majoritarian electoral systems with few effective parties (US, UK and Canada). Our study is conducted in Denmark, a context with a proportional electoral system and with eight parties represented in the parliament at the time of the study. The analysis thereby provides a test of whether the bandwagon effect is present in yet another context, which would bolster those who might claim that the bandwagon effect does not depend on context but is perhaps 
a universal feature of individuals' political cognition. Furthermore, because of the large sample size, we are able to examine whether the bandwagon effect varies across different types of individuals; analyses which can further inform the question of whether the bandwagon effect is universal or contingent.

\section{Experimental design}

In order to examine the bandwagon effect we conducted a survey experiment where we randomly split respondents into five different groups, and presented four of these groups with varying information about the current support for two different parties: the Social Democratic party and the Conservative party. After presenting this information, we asked the respondents a series of questions about their political beliefs and voting intentions. Below we detail the data, the different treatments, and the dependent variable of the survey experiment.

\section{Data}

The data stems from a web-survey carried out by YouGov in their internet panel of Danish voters from January $10^{\text {th }}$ through $28^{\text {th }}, 2014$. Within the panel, 6,941 were invited to participate in the survey via e-mail. 3,011 respondents or 43.4 percent completed the entire survey, which is satisfactory for this type of study. The complete questionnaire can be found in Dahlgaard et al. $(2015 ; 2016)$. These respondents are approximately representative to Danish voters on demographic characteristics and make up a diverse sample of Danish voters. The analysis below only includes answers of those who completed the entire questionnaire. ${ }^{3}$

\section{Treatment}


We randomly split respondents into five groups. Four of the groups read only one of four fictive article from a newspaper including a poll (henceforth the treatment groups). The last group did not read any articles (henceforth the control group). A randomization check showed that both gender, age, education and party choice in the last election was unrelated to treatment allocation, indicating that the randomization was successful. ${ }^{4}$ The layout of the articles was like a real newspaper and four political journalists from different newspapers read and commented on the article and approved of the realistic nature of the articles (for the articles see appendix A). To make sure that the respondents read the article they had to stay on the screen displaying the article for at least 30 seconds.

Each article included a graphical representation of a fictive poll result for a party, the standing for this party in the latest poll, and its standing at the latest election. The standing in the latest poll was arrived at by looking at an average of polls at the time of the survey and thereby presents a highly realistic baseline for the fictive poll to be compared with. ${ }^{5}$ This graph was put into context by a short article describing the poll and an interview with a pundit, a professor in political science, who commented on the consequences of the poll in vague and general terms.

Evidently, each treatment condition included a bundle of manipulations: the poll result, its graphical display, and the journalistic coverage. Consequently, we cannot directly ascribe an effect to either the result of the poll or the article. However, separating these effects seem less meaningful than identifying the effect of a realistic dissemination. A poll is usually combined with a short article describing the result and consequences of the poll, a comparison with past election or polling results, and pundits, including political science professors, routinely weigh in on such trends. For this study, we prioritized real-world authenticity over untangling the effects of each subtle manipulation. Including several manipulations in the treatment thus raises the ecological validity of the treatment, as the treatment is likely to reflect how voters experience polls outside the 
experiment. ${ }^{6}$ See online supporting information appendix A for the original treatments experienced by the respondents.

Party (the Social Democrats and Conservatives) and poll results (gaining and loosing) organized the four treatments. The two parties were the large executive party the Social Democrats, and the small opposition party the Conservatives. At the time the Social Democrats polled around 21 percent in aggregated polls, while the Conservatives polled around four percent. In the Social Democrats-treatments the party gained or lost five percentage points, in the Conservatives-treatment the party gained or lost two percentage points. Accordingly, the smaller Conservative party moved less in the fictive polls.

We chose these particular movements, because we wanted the poll results to be both credible and meaningful. Adding or subtracting five percentage points to a currently small party would seem unrealistic, while changing support for the Social Democrats with two percentage points might fail to incite a feeling of real movement for the party. One drawback of the manipulations is that the sizes of the movements are not directly comparable in either an absolute or relative scale. Also, the graphs are not the same across treatment conditions, and the second axis varied and was even cut off above zero for the large party, something we would usually consider unacceptable dissemination but is nonetheless not unusual for graphs in newspapers.

However, even if the movements were comparable on some scale, it is unclear if one would expect the effects to be similar for small and large parties. Furthermore, the differences in manipulations, including varying the layout of the graphs slightly, do seem to reflect realistic representations of how voters meet polls in the media. Importantly, all the variations are between subjects. The respondents were only exposed to one treatment condition and thus could not compare differences in treatments or become confused by them. Consequently, our study will inform us on 
how disseminations of what can be perceived as big changes for a large as well as a small party affect support among voters. At the end of the survey, we debriefed respondents and informed them of the parties' actual current support.

\section{Dependent variable}

In order to examine whether the popularity of the party as presented in the poll affected respondents' voting intention we simply used the typical question posed by polling companies: "If a parliamentary election was held tomorrow, who would you vote for?". For the roughly ten percent of respondents who answered "don't know", we prodded them by asking them about whether they were leaning towards a particular party, which cut the number of don't knows down to five pct. Polling companies routinely do this for Danish voters, and the rates of “don't knows" were similar across treatment conditions both before and after prodding the voters.

Aside from this question, we also used two other questions. Namely, the probability of voting for the two parties, and sympathy towards the two parties included in the polls both measured on a scale from zero to ten. In order to reduce experimenter demand effects, we asked these questions for all parties eligible to run for parliamentary elections at the time. However, due to limited space, we have refer readers to the supporting information appendix $\mathrm{C}$ regarding these outcomes.

\section{Results}

Figure 1 presents the proportion intending to vote for the Social Democrats or the Conservatives across the treatment's relevant for these parties (lost votes, control, win votes). Overall, there is some evidence of a bandwagon effect, as those who read a news story with a poll about a party winning votes seem more inclined to vote for the party than those who got a poll indicating that the party was losing votes. These differences seem to be larger for the Social Democratic party than for 
the Conservative party, and when comparing to the control group, larger for the treatments which showed the parties gaining electoral support than for the treatments which showed the parties losing electoral support.

For statistical inference, we estimate a multinomial logit model of whether respondents voted for the Social Democrats, the Conservatives or some other party, using the treatment dummies as independent variables. The confidence intervals of electoral support are also presented in figure 1 . The statistical tests we perform are comparisons of the predicted probabilities from our multinomial logit model across different outcomes (i.e. parties) and different treatments.

We find, for both parties, that receiving a poll in which a party wins votes makes one more inclined to vote for this party than if one receives a poll in which the party lose votes $(p<0.05)$. We also find a statistically significant difference in intention to vote for a party between those who received no poll and those who received a poll showing the party winning votes, however for each party it is only statistically significant at the ten percent level in a one-sided test. Finally, we find no statistically discernable difference between receiving no poll and receiving a poll showing the party losing votes, though the point estimates are negative as expected.

\section{Figure 1: about here}

In order to maximize the statistical leverage of the experiment we also test the joint effects of receiving a type of election poll (gain or loss) on the probability of voting for the party that the election poll was about (see online supporting information appendix B for details of this test). Using this method, we find that the joint difference in probability of voting for a party between the control group and the group receiving a poll, which showed the party gaining electoral momentum is both positive and statistically significant $(\mathrm{p}<0.05)$. The difference between receiving a poll, which shows the party losing electoral momentum and the control group is negative but not statistically 
significant $(\mathrm{p}<0.4)$. Accordingly, the data indicates that a poll showing an electoral gain for a party increases support for this party more than a poll showing an electoral loss reduces support for this party. However, the differences in size between the positive and negative effects are not significant $(\mathrm{p}<0.5)$

In summary, those who were presented with a news article with a poll showing a party gaining electoral support were statistically significantly more likely to vote for this party than those in the control group and those who received a poll showing the party loosing electoral support. This provides evidence for the bandwagon hypothesis. Parties with electoral fortune in election polls are more attractive to voters. That is, voters are more likely to vote for a party if they have read an article, which shows this party gaining rather than losing in the polls. In addition, we find similar results for voter's self-reported probability of voting for the party and their sympathy for the party (online supporting information appendix C).

\section{Heterogeneity in the bandwagon effect}

On average, subjects who were exposed to a news article with a poll indicating that a party was winning votes were more likely to vote for this party, but one might ask whether certain types of subjects were more affected by the polling information than others. This is potentially interesting because it can tell us something about the universality of the bandwagon effect, and accordingly it might also tell us something about the mechanisms underlying the bandwagon effect.

We had no prior expectation about what kind of treatment heterogeneity we might see, and accordingly the heterogeneity analysis should be seen as purely explorative, and any conclusions, positive or negative, should be considered as objects for future examination. We use available pretreatment variables and look at effects for those above and below the median age; 
gender; those with a high school education or less and those with more; those who voted for the party at the last election and those who did not.

To investigate how sensitive these different groups were to the treatment effect, we estimated the average marginal effect of receiving a "win poll" rather than a "loss poll" across different groups and for each of the two parties. The average marginal effects were derived from logistic regressions of intention to vote for one of the two parties, using a treatment dummy (i.e. "win poll" or "loss poll") and a dummy indicating, which group the respondent was in (e.g. man or woman). The average marginal effects for the different groups are plotted in figure 2.

\section{Figure 2: about here}

Figure 2 shows little heterogeneity in the treatment effect. None of the four different ways of slicing up the subjects leave us with any statistically significant differences in the average marginal effects for either of the two parties. Consistent with an interpretation of the bandwagon effect being a more general phenomenon, there is no indication that the effect is particular to any demographic group.

\section{Discussion}

We conducted a survey experiment where voters were presented with a poll and a short newspaper article describing either increased or decreased electoral support for one of two Danish parties. Across both parties, voters were more likely to intent to vote for the party if the poll showed increased electoral support than if presented with no poll or a poll showing decrease in electoral support for the party. This provides evidence for the bandwagon hypothesis in the survey experiment: voters flock towards parties that show electoral strength. 
We cannot be sure how voters will react in the same way when presented to poll stories in the real world. In real life, voters are exposed to several polls, they might be exposed to the same poll several times, a poll gets interpreted in different ways and some voters might not notice the poll at all. Furthermore, the long-term effect of exposure to a poll is not captured by our study. Also, our study examines voting intentions, which is only relevant in so far as it provides a good proxy for actual voting behavior. An obvious extension of our study would be to examine the effect on actual voting behavior. In addition, our treatments for the two parties are not fully comparable and the strongest push for parties in the manipulation leads to the strongest effects. Perhaps a coincidence, but future research could explore if there is a relationship between a party's change in support and the size of the effect, and perhaps even characterize the shape of such a relationship, should it exist. Another thing that we do not consider is strategic considerations such as voting for a party with the intent of keeping another out of the power, affecting the balance of power in coalition governments, and taking a threshold into account (Jenssen 2016). These may intersect with the bandwagon effect. ${ }^{7}$

Our findings add to a growing literature on bandwagon effects in European democracies (van der Meer et al. 2015, Stolwijk et al. 2016; Morton et al. 2015), and ongoing debates about dissemination of polls perhaps even more relevant than ever considering some recent polling and prediction failures of political journalists and pundits (Donsbach 2001; cf. Aalberg \& Van Aelst 2014; Petersen 2012). We found consistent effects across different parties, and different types of voters, for a diverse national sample, in a political context very different from those of earlier research on the bandwagon effects. Accordingly, our findings are in line of an account of bandwagon behavior, which is based not on social or political contingencies, such as media or political institution, but on fundamentals of human political cognition. 
In our study, we present voters with a bundle of manipulations in each treatment, and we are unable to identify how each element contributes to the total effect. It would be interesting for further research to explore exactly what parts of the polling information and political cognition that leads voters towards political parties with electoral strength. 


\section{References}

Albrechtsen, K. 2013. Enigt Folketing vil afskaffe meningsmålinger på valgdagen. Berlingske Nyhedsbureau, 20.11.2013.

Ansolabehere, S. \& Iyengar, S. 1994. Of horseshoes and horse races: Experimental studies of the impact of poll results on electoral behavior. Political Communication, 11(4): 413-430.

Bernays, E. L. 1945. Attitude Polls-Servants or Masters? Public Opinion Quarterly, 9(3): 264-268.

Brady, H. \& McNulty, J. 2011. Turning out to vote: The costs of finding and getting to the polling place. American Political Science Review, 105(1): 115-134.

Ceci, S. J. \& Kain, E. L. 1982. Jumping on the bandwagon with the underdog: The impact of attitude polls on polling behavior. Public Opinion Quarterly, 46(2): 228-242.

Dahlgaard, J. O., Hansen, J. H., Hansen, K. M. \& Larsen, M. V. 2015. Hvordan påvirkes vælgerne af meningsmålinger? Effekten af meningsmålinger på danskernes stemmeadfærd og sympati for partierne. Politica, 47(1): 5-23.

Dahlgaard, J. O., Hansen, J. H., Hansen, K. M. \& Larsen, M. V. 2016. How are Voters Influenced by Opinion Polls? The Effect of Polls on Voting Behavior and Party Sympathy. World Political Science, 12(2): 283-300.

Ditlevsen, S. D. 2009. Valg: Exit-polls undergraver demokratisk debat i valgkampe. Information, 11.06.2009.

Donsbach, W. 2001. Who's Afraid of Election Polls?: Normative and Empirical Arguments for the Freedom of Pre-election Surveys: Foundation for Information.

Erikson, R. S. \& Stoker, L. 2011. Caught in the draft: The effects of Vietnam draft lottery status on political attitudes. American Political Science Review, 105(02): 221-237.

Field, H. H., Lazarsfeld, P. F., Robinson, C. G. \& Bernays, E. L. 1945. The Discussion goes on. Public Opinion Quarterly: 403-410.

Gallup, G. \& Rae, S. F. 1940. Is there a bandwagon vote? Public Opinion Quarterly, 4(2): 244-249.

Gerber, A. S., Huber, G. A., Doherty, D. \& Dowling, C. M. 2011. The big five personality traits in the political arena. Annual Review of Political Science, 14: 265-287.

Hardmeier, S. 2008. The effects of published polls on citizens. The SAGE Handbook of Public Opinion Research. Los Angeles: Sage: 504-513.

Hernadi, A. 2010. Statsvetare skeptisk till opinionsförbud. Svenska Dagbladet, 03-09-2010.

Jakobsen, M. S., Wichman, J. M. \& Siegumfeldt, F. 2005. Meningsmålinger - påvirker de vælgerne? Berlingske Tidende, 04.12.2005.

Jenssen, A. T. 2016. Tactical Voting in Norway: Context, Motives and Occurrence. Scandinavian Political Studies, 39(1): 22-51.

Kay, A. C., Jimenez, M. C. \& Jost, J. T. 2002. Sour grapes, sweet lemons, and the anticipatory rationalization of the status quo. Personality and Social Psychology Bulletin, 28(9): 1300-1312.

Kleinnijenhuis, J., Van Hoof, A. M., Oegema, D. \& De Ridder, J. A. 2007. A Test of Rivaling Approaches to Explain News Effects: News on Issue Positions of Parties, Real-World Developments, Support and Criticism, and Success and Failure. Journal of Communication, 57(2): 366-384.

Lau, R. R. \& Redlawsk, D. P. 2001. Advantages and disadvantages of cognitive heuristics in political decision making. American Journal of Political Science, 45(4): 951-971.

Leibenstein, H. 1950. Bandwagon, snob, and Veblen effects in the theory of consumers' demand. The Quarterly Journal of Economics, 64(2): 183-207.

Marsh, C. 1985. Back on the bandwagon: The effect of opinion polls on public opinion. British Journal of Political Science, 15(01): 51-74.

Meffert, M. F., Huber, S., Gschwend, T. \& Pappi, F. U. 2011. More than wishful thinking: Causes and consequences of voters' electoral expectations about parties and coalitions. Electoral Studies, 30(4): 804-815.

Mondak, J. J. 2010. Personality and the Foundations of Political Behavior: Cambridge University Press.

Morton, R. B., Muller, D., Page, L. \& Torgler, B. 2015. Exit polls, turnout, and bandwagon voting: Evidence from a natural experiment. European Economic Review, 77: 65-81. 
Mutz, D. C. 1997. Mechanisms of momentum: does thinking make it so? The Journal of Politics, 59(01): 104-125.

Petersen, T. 2012. Regulation of opinion polls: A comparative perspective. Opinion Polls and the Media. Reflecting and Shaping Public Opinion: 47-68.

Rothschild, D. \& Malhotra, N. 2014. Are public opinion polls self-fulfilling prophecies? Research \& Politics, 1(2): 1-10.

Sandvik, S., Viseth, E., Fossen, C. \& Jakobsen, R. 2013. Krisemåling kaster Lysbakken ut av tinget. NRK, 16.08.2013.

Simon, H. A. 1954. Bandwagon and underdog effects and the possibility of election predictions. Public Opinion Quarterly, 18(3): 245-253.

Skjoldan, L.-L. 2015. Medieordførere: Problematisk med exit polls på valgdag. Altinget, 15.06.2015.

Stolwijk, S. B., Schuck, A. R. \& De Vreese, C. H. 2016. How Anxiety and Enthusiasm Help Explain the Bandwagon Effect. International Journal of Public Opinion Research: edw018.

Van Der Meer, T. W., Hakhverdian, A. \& Aaldering, L. 2016. Off the fence, onto the bandwagon? a largescale survey experiment on effect of real-life poll outcomes on subsequent vote intentions. International Journal of Public Opinion Research, 28(1): 46-72.

Aalberg, T. \& Van Aelst, P. 2014. Who Is Afraid of Preelection Polls? How Perceptions of Polls Influence Support for Polling Regulations among Elites. International Journal of Public Opinion Research, 26 (4): $517-530$.

\footnotetext{
${ }^{1}$ This research note extends on a findings published in Dahlgaard et al. (2016). The added contribution in the research note is to relate the findings to recent, related publications and present heterogeneity analyses that have not previously been published. We would like thanks the editors and reviewers for their constructive comments.

2 As an example one of the parties of the study, the Social Democratic Party, experienced increased electoral support in the 2015 national election but lost executive power due to their coalition partners loss of mandates.

$3 \mathrm{We}$ also performed the analysis including those respondents who only completed part of the questionnaire. This does not substantially change the effect sizes or statistical significance. There were no differences in attrition rates across the different experimental groups.

${ }^{4}$ Tested using multinomial logit regression $(\mathrm{p}>0.5)$.

${ }^{5}$ In weighted averages of polls, the Conservatives did not experience much variation in support around the time of the data collection compared to the previous election. The real poll average was 4.5 percent for Conservative at time of the data collection. The Social Democratic Party had experienced a surge on app. four percentage points three months before the data collection, but had lost three percentage points again at the time of study. In the months after the election, both the Conservatives and the Social Democratic Party gained quite stable support in the polls. Finally, it is noted that single polls often deliver larger changes in support than what is tracked in the weighted average. The current support for the two parties was mentioned in the debriefing of the respondents in the survey.

${ }^{6}$ At the end of the survey, respondents were asked about the content of the article they read in the beginning of the survey as a manipulation check. Out of the 2,407 respondents who saw one of the articles (control group excluded) 89 percent were correct, 11 percent were wrong or replied "do not know" on the question about the article they were presented to. I.e. the vast majority had read the article intensively enough to be able to repeat the heading and we can conclude that they were exposed to the increase or decline in party support.

${ }^{7} \mathrm{We}$ thank an anonymous reviewer for bringing this to our attention.
} 